\title{
Discontinuous ventilator weaning of patients with acute $\mathrm{SCI}$
}

\author{
Wout Füssenich ${ }^{1,2} \cdot$ Sven Hirschfeld Araujo ${ }^{1} \cdot$ Birgitt Kowald $^{3} \cdot$ Allard Hosman $^{2} \cdot$ Marc Auerswald $^{1} \cdot$ Roland Thietje $^{1}$
}

Received: 9 June 2017 / Revised: 10 December 2017 / Accepted: 13 December 2017 / Published online: 16 January 2018

(c) International Spinal Cord Society 2018

\begin{abstract}
Study design Retrospective, single centre cohort study.

Objectives To determine factors associated with ventilator weaning success and failure in patients with acute spinal cord injury (SCI); determine length of time and attempts required to wean from the ventilator successfully and determine the incidence of pneumonia.

Setting BG Klinikum Hamburg, Level 1 trauma centre, SCI Department, Germany.

Methods From 2010 until 2017, 165 consecutive patients with cervical SCI, initially dependent on a ventilator, were included and weaned discontinuously via tracheal cannula. Data related to anthropometric details, neurological injury, respiratory outcomes, and weaning parameters were prospectively recorded in a database and retrospectively analysed.

Results Seventy-nine percent of all patients were successfully weaned from ventilation. Average duration of the complete weaning process was 37 days. Ninety-one percent of the successfully weaned patients completed this on first attempt. Age ( $>56$ years), level of injury (C4 and/or above), vital capacity $(<1500 \mathrm{ml})$, obesity $\left(>25 \mathrm{~kg} / \mathrm{m}^{2}\right)$, and chronic obstructive pulmonary disease (COPD) significantly decreased the chance of successful weaning. These factors also correlated with a higher number of weaning attempts. High level of injury, older age, and reduced vital capacity also increased the duration of the weaning process. Patients with low vital capacity and concurrent therapy with Baclofen and Dantrolene showed higher rates of pneumonia.

Conclusions We conclude that mentioned factors are associated with weaning outcome and useful for clinical recommendations and patient counselling. These data further support the complexity of ventilator weaning in the SCI population due to associated complications, therefore we recommend conducting weaning of patients with SCI on intensive or intermediate care units (ICU/IMCU) in specialised centres.
\end{abstract}

\section{Introduction}

Patients with newly acquired cervical spinal cord injury (SCI) commonly require mechanical ventilation. Since the diaphragm is innervated by $\mathrm{C} 3-\mathrm{C} 5$, lesions above or within

Wout Füssenich and Sven Hirschfeld Araujo contributed equally to this work.

Wout Füssenich

woutfussenich@gmail.com

1 Centre for Spinal Injuries, BG Trauma Hospital Hamburg, Hamburg, Germany

2 Department of Orthopedic Surgery, Radboud University Medical Centre, Nijmegen, The Netherlands

3 Biomechanics Laboratory, BG Trauma Hospital Hamburg, Hamburg, Germany these levels will increase the likelihood of ongoing ventilator dependency and therefore these individuals without sufficient diaphragm function cannot be weaned from mechanical ventilation. SCI below these levels also affects the ventilatory function due to significant impairment of additional respiratory muscles such as intercostal and/or abdominal muscles $[1,2]$. When the patient is stabilised on intensive or intermediate care units (ICU/IMCU) and develop sufficient vital capacity (VC) while breathing spontaneously (approx. $1000 \mathrm{ml}$ ), the weaning process can be initiated [3]. Cervical SCI and complete paralysis are significantly associated with a prolonged weaning process, which is defined by a duration $>7$ days $[4,5]$. Therefore, the incidence of tracheostomy and invasive ventilation is high and around $30 \%$ of the ventilated patients with SCI remain ventilator dependent due to weaning failure [6-8]. Prolonged weaning also is associated with a higher incidence of respiratory complications, mortality and high health care expenditures [9-12], and while these patients only represent 
6-10\% of all those who are mechanically ventilated they consume $37-50 \%$ of all ICU resources [13, 14]. In addition, the number and life expectancy of patients with SCI and ventilator dependency will increase due to improved medical care during emergency treatment and after discharge from hospital [15-19]. Several studies with significantly fewer patients or that were conducted outside specialised SCI centres have described factors associated with prolonged weaning and weaning failure in patients with SCI, such as level of injury [20], American Spinal Injury Association Impairment Scale (AIS) [2], spirometry results [21], respiratory complications $[9,22]$, and pre-existing lung disease [23]. Therefore, the aim of this study was to verify the published factors for weaning success or failure within a SCI centre to identify new factors such as value ranges (VC, body mass index (BMI), age), diaphragm function and the influence of concurrent Baclofen or Dantrolene therapy to prevent frustrating weaning attempts and to reduce weaning failure quotes.

\section{Methods}

\section{Subjects}

Consecutive patients with acute SCI were invasively weaned via tracheal cannula between 1 January 2010 and 31 December 2016 on ICU or IMCU. All patients suffered traumatic or non-traumatic SCI and were referred from hospitals that provide primary care but no specialised treatment for patients with SCI [24]. The average time between onset of lesion and admission to our hospital was 24 days (median 20, range 0-120 days). Patients classified from AIS A to D were included for statistical analysis, if they had at least one weaning attempt in our department within the above-mentioned period. We excluded all patients under 18 years of age and those without diaphragm function or central sleep-related respiratory disorders. Patients with AIS C0-C3 $\mathrm{A}$ and $\mathrm{B}$ were included only if significant motor diaphragm functions were present (AIS A: zones of motor preservation, AIS B: transition segments with motor functions).

\section{Study design}

Retrospective analysis of a monocentric cohort study collecting anthropometric data including gender, age, traumatic or non-traumatic SCI, level of lesion and AIS scale defined by American Spinal Injury Association standards [25], height and weight to calculate BMI, VC measured by bedside spirometry in supine position according to European Respiratory Society/American Thoracic Society standards [26] medicinally treated COPD Global Initiative for Chronic Obstructive Lung Disease 3, diaphragm function defined by echo sonography $[27,28]$ and the use of two muscle relaxant medications, Baclofen and Dantrolene were recorded.

\section{Practical course}

The weaning process was executed entirely on the ICU or IMCU of the SCI centre with recording of the following vital parameters: (1) respiratory rate; (2) current tidal volume (TV); and (3) end expiratory level of carbon dioxide (capnometry). Clinically stable patients were ventilated with pressure control ventilation (PCV). The ventilator standard settings were: inspiratory pressure $8-25 \mathrm{~cm} \mathrm{H}_{2} \mathrm{O}$, frequency $8-16 / \mathrm{min}$, inspiratory time (T-in) $1.5-2.5 \mathrm{~s}$, and positive end-expired pressure $2-8 \mathrm{~cm} \mathrm{H}_{2} \mathrm{O}$. Weaning was commenced when the patient could achieve a minimum $\mathrm{VC}$ of $500 \mathrm{ml}$ and carried out during the hours of 08:00 and 20:00 h. Discontinuous weaning meant that the patient had a period of spontaneous (training) breathing followed by time on the ventilator (recovery) during every full hour. In clearly defined steps of 5-10 min per hour, the training units (minimum 8, max 12) were increased day by day, until the patient was breathing spontaneously $12 \mathrm{~h}$ without any ventilator support. The night-time weaning was started 3 days later and increased by $1 \mathrm{~h}$ per night. The convalescence of all respiratory muscles was ensured by the mentioned PCV breathing mode. All training cycles were recorded at the beginning and at the end including the following parameters: TV, respiratory rate, oxygen and carbon dioxide saturation, blood pressure, and heart rate [29].

Weaning attempts were interrupted when at least one of the following events occurred: (1) pneumonia; (2) septicaemia (e.g., due to spondylodiscitis or pressure sores); (3) fever $>38.5^{\circ} \mathrm{C}$; (4) complete paralysis of the diaphragm; (5) significantly decreased TV with oxygen desaturation $\left(\mathrm{SpO}_{2}\right.$ $<90 \%$ ) and/or hypercapnia (>50 mmHg); (6) relevant autonomic dysreflexia; (7) pronounced spasticity of relevant respiratory muscles; (8) constant heart rate $>140 \mathrm{bpm}$; (9) respiratory rate $>35 / \mathrm{min}$; (10) metabolic acidosis; (11) inadequate mental status; or (12) general anaesthesia (e.g., in case of bronchoscopy).

\section{Outcome measures}

\section{Weaning success}

Defined as absence of mechanical ventilation for at least 7 days.

\section{Weaning failure}

Defined as (1) requiring ventilator support because of failed spontaneous breathing trials; or (2) restart of mechanical ventilation $[5,8]$. 
Table 1 Clinical details for both groups

\begin{tabular}{|c|c|c|c|c|}
\hline Variables & Total & Success & Failure & $p$-value \\
\hline \multicolumn{5}{|l|}{ Sex } \\
\hline Male & 131 & $105(80 \%)$ & $26(20 \%)$ & $0.6^{\mathrm{a}}$ \\
\hline Female & 34 & $26(76 \%)$ & $8(24 \%)$ & \\
\hline Age (years) & & & & $<\mathbf{0 . 0 1}^{\mathrm{b}}$ \\
\hline Range & $18-87$ & $18-85$ & $56-87$ & \\
\hline Mean \pm SD & $57.2 \pm 17.3$ & $53.7 \pm 17.2$ & $70.6 \pm 9.0$ & \\
\hline Median & 60 & 56.0 & 72.5 & \\
\hline Neurological level & & & & $<0.01^{\mathrm{a}}$ \\
\hline $\mathrm{C} 0-\mathrm{C} 4$ & 103 & $74(71 \%)$ & $29(29 \%)$ & \\
\hline $\mathrm{C} 5-\mathrm{C} 8$ & 30 & $28(93 \%)$ & $2(7 \%)$ & \\
\hline $\mathrm{T} 1$ or lower & 32 & $29(91 \%)$ & $3(9 \%)$ & \\
\hline $\begin{array}{l}\text { Severity of } \\
\text { neurological deficit }\end{array}$ & & & & $0.06^{\mathrm{a}}$ \\
\hline AIS A & 75 & $63(84 \%)$ & $12(16 \%)$ & \\
\hline AIS B & 20 & $13(65 \%)$ & $7(45 \%)$ & \\
\hline AIS C & 52 & $38(73 \%)$ & $14(27 \%)$ & \\
\hline AIS D & 18 & $17(94 \%)$ & $1(6 \%)$ & \\
\hline Cause of SCI & & & & $0.7^{\mathrm{a}}$ \\
\hline Traumatic & 132 & $104(78 \%)$ & $28(22 \%)$ & \\
\hline Non-traumatic & 33 & $27(81 \%)$ & $6(19 \%)$ & \\
\hline \multicolumn{5}{|l|}{ Comorbidity } \\
\hline Pneumonia & $19(12 \%)$ & $13(68 \%)$ & $6(32 \%)$ & $0.2^{\mathrm{c}}$ \\
\hline 4 COPD GOLD3/ & $13(8 \%)$ & $8(62 \%)$ & $5(38 \%)$ & $0.14^{\mathrm{c}}$ \\
\hline BMI $\left(\mathrm{kg} / \mathrm{m}^{2}\right)$ & & & & $0.01^{b}$ \\
\hline Range & $18.0-51.4$ & $18.0-51.4$ & $27.0-47.3$ & \\
\hline Mean \pm SD & $25.4 \pm 539$ & $22.1 \pm 5.8$ & $28.4 \pm 6.2$ & \\
\hline Median & 24.6 & 23.4 & 26.3 & \\
\hline Vital capacity (ml) & & & & $0.05^{\mathrm{b}}$ \\
\hline Range & $500-3400$ & $500-3400$ & $500-1500$ & \\
\hline Mean & $1246 \pm 539$ & $1304 \pm 578$ & $1021 \pm 247$ & \\
\hline Median & 1100 & 1200 & 1000 & \\
\hline $\begin{array}{l}\text { Diaphragm } \\
\text { function }\end{array}$ & $n=161$ & $n=128$ & $n=33$ & $0.4^{\mathrm{a}}$ \\
\hline Normal & 135 & $110(88 \%)$ & $25(12 \%)$ & \\
\hline Hemiplegia & 21 & $15(71 \%)$ & $6(29 \%)$ & \\
\hline Pre-treatment period & & & & $\mathbf{0 . 0 2 ^ { b }}$ \\
\hline Range & $0-120$ & $0-120$ & $0-115$ & \\
\hline Mean \pm SD & $24 \pm 20$ & $22 \pm 19$ & $31 \pm 24$ & \\
\hline Median & 20 & 18 & 24.5 & \\
\hline $\begin{array}{l}\text { Weaning time } \\
\text { (days) }\end{array}$ & & & & $<0.01^{b}$ \\
\hline Range & $6-280$ & $6-126$ & $25-280$ & \\
\hline Mean \pm SD & $45 \pm 36$ & $37 \pm 25$ & $73 \pm 54$ & \\
\hline Median & 32 & 28 & 53 & \\
\hline
\end{tabular}

Table 1 (continued)

\begin{tabular}{lllll}
\hline Variables & Total & Success & Failure & $p$-value \\
\hline Weaning attempts & $n=165$ & $n=131$ & $n=34$ & $\mathbf{< 0 . 0 1}^{\text {a }}$ \\
1 & 124 & $113(91 \%)$ & $11(9 \%)$ & \\
2 & 36 & $17(47 \%)$ & $19(53 \%)$ & \\
$>2$ & 5 & $1(2 \%)$ & $4(80 \%)$ & \\
\hline
\end{tabular}

Bold signifies $p<0.05$

Percentages describe the part of total group. $p$-values concern differences between success and failure group

${ }^{a}$ Fisher's exact test

${ }^{\mathrm{b}}$ Wilcoxon rank-sum test

c $\chi^{2}$ test

\section{Duration of weaning}

Defined as the number of days between the day the weaning process was started and the last day the patient was mechanically ventilated. In case of failure, the end of this period was set as the day the existing situation. At all times of measurement patients were ventilated and breathed via the tracheal cannula to avoid possible influence of upper airway obstructions (e.g., obstructive sleep apnoea syndrome) in terms of weaning failure.

\section{Weaning attempts}

Defined as an attempt when the weaning process was interrupted for more than 1 week. Due to clinical stability, we performed a maximum of three attempts.

\section{Rate of pneumonia}

Defined as a diagnosis by the attending physician according to the S-3 Guideline Epidemiology, Diagnosis and Treatment of Adult Patients with Nosocomial Pneumonia compiled by various German Societies [30].

\section{Informed consent}

At the start of weaning, all patients were in a healthy mental status, had full legal capacity in every aspect, and signed a declaration of consent following detailed information.

\section{Statement of ethics}

We certify that all applicable institutional and governmental regulations concerning the ethical use of human volunteers were followed during the course of this research. 


\section{Statistics}

Categorical data were analysed with $\chi^{2}$ test or Fisher's exact test; continuous data were verified with Wilcoxon rank-sum test or Kruskal-Wallis tests. Tests were performed by SAS and considered significant at $p \leq 0.05$.

\section{Results}

\section{In-excluding ratio}

A total of 174 patients with SCI underwent the weaning procedure. Nine patients were excluded because of age below 18 (3), injury level C0-C2 AIS type A without any diaphragm function (2), and an incomplete weaning process (2). Furthermore, two patients died during the weaning process from pneumonia and septicaemia due to spondylodiscitis.

Therefore, a total of 165 patients were statistically analysed (Table 1). One hundred thirty-one (79\%) patients were male. Mean age was 57.2 years (median 60 years) with a distribution of AIS score; A: 75 (45\%), B: 20 (12\%), C: 52 (32\%), D: 18 (11\%). Level of lesion: C0-C4: 103 (62\%), C5-C8: 29 (18\%), T1-S5: 33 (20\%). In 132 (80\%) patients the SCI was caused traumatically. Thirteen (8\%) patients had clinically apparent COPD (all stage of GOLD 3). Patients with a BMI $>25 \mathrm{~kg} / \mathrm{m}^{2}$ showed significantly higher failure rates. Regarding the weaning failure group (34 patients $=21 \%$ ), one (3\%) patient remained fully ventilator dependent, one (3\%) for $18 \mathrm{~h}, 27$ patients $(79 \%)$ needed night-time ventilation from 10 to $12 \mathrm{~h}$, and three (9\%) patients for $6 \mathrm{~h}$. Two were ventilated only on demand ranging widely from 3 to over $12 \mathrm{~h}$ per day. Fifty-four patients took Baclofen orally in a mean dose of $60 \mathrm{mg} / \mathrm{day}$, five patients intrathecally in a mean dose of $318 \mathrm{mg} / \mathrm{day}$, and seven patients took Dantrolene orally in a mean dose of $103 \mathrm{mg} /$ day.

\section{Success vs. failure}

One hundred thirty-one patients $(79 \%)$ were successfully weaned, with a failure rate of $21 \%$. Those who successfully weaned were, on average, 16.9 years younger $(p<0.01)$. Likewise, level of injury differed significantly between the success and failure group $(p<0.01)$, whereas AIS score only resulted in a trend $(p=0.06)$. Combined success rates for level of injury and AIS score for weaning success are displayed in Fig. $1(p=0.01)$. On average, those who successfully weaned had a higher VC (1304 vs. 1021 $\mathrm{ml}, p=0.05$ ) (Table 1; Fig. 2) and a normal BMI $(p=0.01)$.

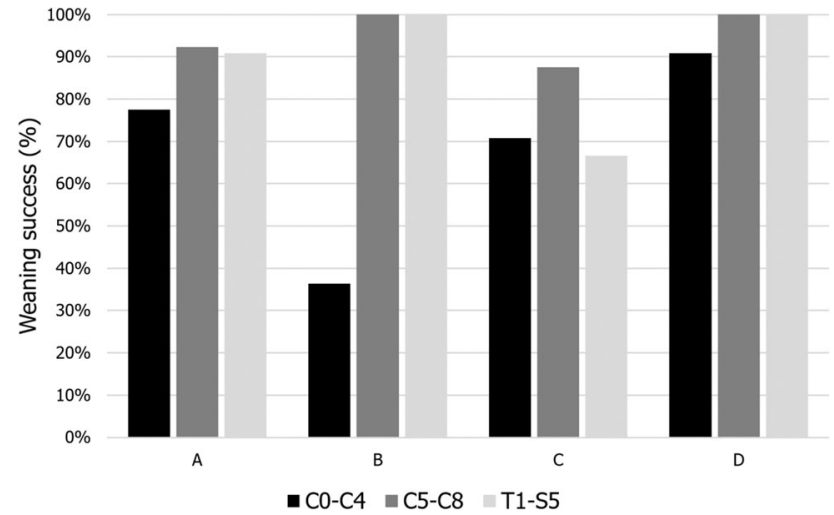

Fig. 1 Rate of weaning success with regard to level of lesion and AIS score

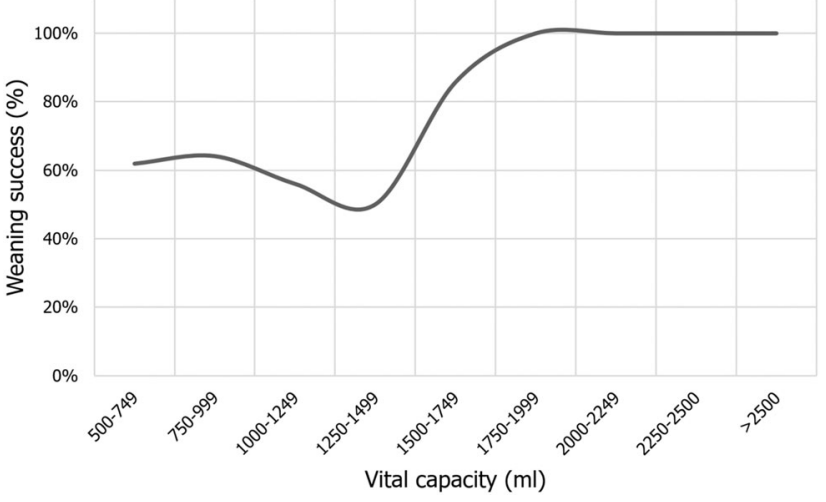

Fig. 2 Rate of weaning success plotted against vital capacity

\section{Duration of weaning}

Average weaning time for the successful group vs. failure group (37 vs. 73 days) differed significantly $(p<0.01)$. The lower the $\mathrm{VC}$ and higher the age, the longer the weaning process took $(p=0.02, p<0.001$, respectively; Figs. 3, 4). Average (SD) duration of the weaning in days for level of injury was: C0-C4: 46.3 (32.2) days, C5-C8: 35.8 (28.8) days, T1 or lower: 48.9 (51.4) days $(p=0.03)$. AIS score, traumatic or non-traumatic SCI, BMI, and the occurrence of pneumonia were analysed but did not differ significantly.

\section{Weaning attempt}

In the successfully weaned group $113(86 \%)$ patients needed one wean attempt, 17 patients $(13 \%)$ required two wean attempts, and one (1\%) more than two attempts. In the failure group 11 patients (32\%) failed after one attempt, 19 patients $(56 \%)$ after two and four $(12 \%)$ attempted to wean more than two times $(p<0.001)$. Again, the lower the VC and higher the age, the more attempts were needed 


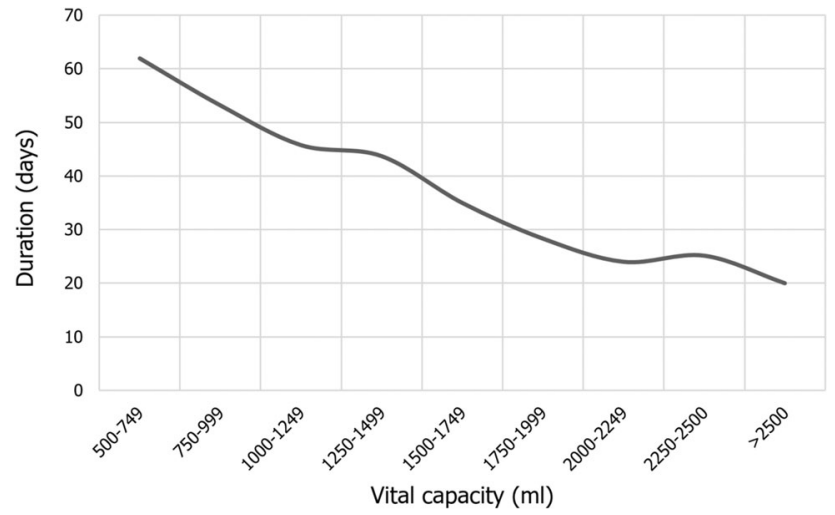

Fig. 3 Average duration of weaning plotted against vital capacity at start of weaning

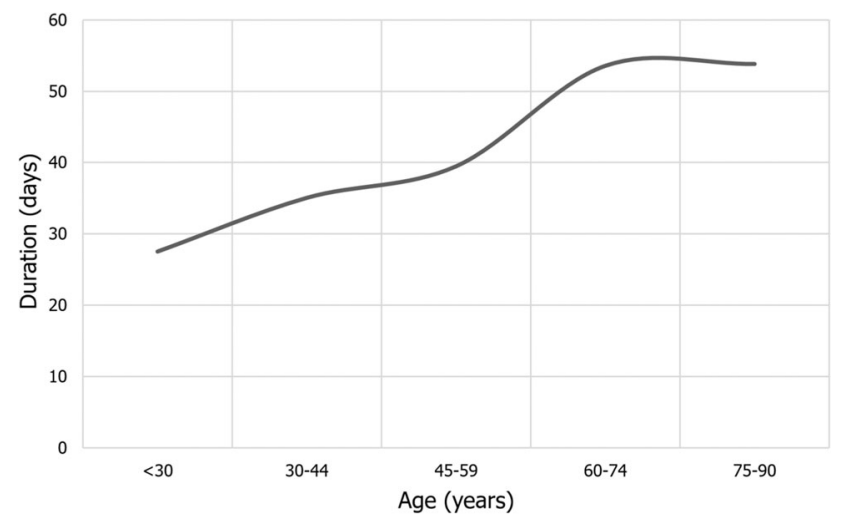

Fig. 4 Average duration of weaning by age

\section{Pneumonia}

During the weaning period 25 patients (14\%) had pneumonia. These patients had, on average, a lower VC $(975 \mathrm{ml}$; $p=0.04)$. Twenty-one percent of the patients using Baclofen and/or Dantrolene had pneumonia in contrast to $4 \%$ of those without these medication $(p<0.001)$. No other factors were found to differ significantly.

\section{Discussion}

\section{Successful weaning and ventilator dependency}

In our study $78 \%$ of the included patients had a level of injury $\mathrm{C} 6$ or above with impaired diaphragm function and were therefore ventilator dependent [1]. Despite this impairment, patients with SCI at $\mathrm{C} 0-\mathrm{C} 3$ and $\mathrm{C} 4-\mathrm{C} 6$ had a weaning success rate of 63 and $88 \%$. Como et al. also described a strong relationship between high level of injury and persistent ventilator dependency or prolonged weaning [20]. We therefore conclude that high level of lesion generally results in impaired muscle function and increases the risk of poor weaning outcome.

AIS score tends to be a decisive factor in weaning success or failure $(p=0.06)$. Therefore, at first glance, the high success percentage of $94 \%$ in patients with AIS D is expected. But considering the factors that $78 \%$ of the

Table 2 Results age and VC for weaning attempts

\begin{tabular}{|c|c|c|c|c|c|}
\hline Variables & Total & 1 attempt & 2 attempts & $>2$ attempts & $p$-value \\
\hline \multicolumn{6}{|l|}{ Age (years) } \\
\hline Range & $18-87$ & $18-87$ & $21-82$ & $58-83$ & $<\mathbf{0 . 0 0 1}^{\mathrm{a}}$ \\
\hline Mean \pm SD & $57.2 \pm 17.3$ & $54.6 \pm 17.1$ & $64.1 \pm 14.6$ & $71.6 \pm 10.9$ & \\
\hline Median & 60 & 56 & 68 & 77 & \\
\hline Vital capacity (ml) & & $n=104$ & $n=31$ & $n=6$ & \\
\hline Range & $500-3400$ & $500-3400$ & $500-1700$ & $700-1000$ & $0.02^{\mathrm{a}}$ \\
\hline Mean \pm SD & $1246 \pm 539$ & $1322 \pm 589$ & $1053 \pm 278$ & $850 \pm 123$ & \\
\hline Median & 1100 & 1200 & 1000 & 800 & \\
\hline
\end{tabular}

Bold signifies $p<0.05$

The numbers represent days of weaning. $p$-values concern significant differences between the three groups

${ }^{a}$ Wilcoxon rank-sum test

(Table 2). Fifty-eight percent of the patients who had pneumonia were weaned during the first attempt, six $(31 \%)$ at the second and two $(11 \%)$ needed further attempts $(p=0.05)$. Within the COPD group, six patients $(46 \%)$ were weaned at the first attempt and five $(38 \%)$ at two attempts. At least two patients $(15 \%)$ needed more attempts $(p<0.001)$. Other analysed factors did not differ significantly. patients with AIS D had a high level of injury (C6 and above) and that only one patient in this category could not be weaned completely, this outcome is remarkable concerning the level of lesion. On the other hand, only $91 \%$ of the patients with a level of injury $\mathrm{T} 1$ or lower were successfully weaned, possibly because of a higher percentage of AIS A classification and severe comorbidities. However, AIS score combined with level of lesion was significant for weaning success $(p=0.01)$, means the higher the level of 
injury and the worse the AIS scoring, the lower the success rate $[2,20,21]$. Furthermore, those with C3 AIS A tetraplegia have a higher success percentage than expected. Forty-seven percent of these patients had zones of partial preservation reaching to at least $\mathrm{C} 4$ or lower. Chiodo et al. found significant results in a small group of 19 patients with an injury level of C2 to C6 AIS A or B. However, they concluded that this is not a solid predictor due to the high variability in the ability to wean. The innervation pattern of the diaphragm may play a role [21]. Moreover, a wide spectrum of zones of partial muscular preservation might interfere with the measurements of outcome according to a clear classification.

The study showed that age is an important factor in the weaning process. All patients under 56 years were successfully weaned. Above this age, the success rates decreased almost linearly. At the average age of 82 the success rate is decreased to $50 \%$. Wicks et al. also published worse weaning outcome in patients above 50 years [31]. However, Chiodo et al. did not measure differences in age for success or failure in their relatively small cohort [21]. Due to our larger patient population and differentiating factors we conclude that high age adversely effects the weaning success. Older age also leads to more weaning attempts $(p<0.001)$ and a longer duration of the weaning $(p<0.01)$ (see Table 2 and Fig. 4).

In our study, patients with low $\mathrm{VC}$ at the start of the weaning process had worse outcomes $(p=0.05)$ (Table 1; Fig. 2). The highest $\mathrm{VC}$ in patients that remained ventilator dependent was $1500 \mathrm{ml}$. The German weaning guideline prescribes that a patient with a VC of at least $1000 \mathrm{ml}$ could start the weaning procedure [5]. In practice, patients with a $\mathrm{VC}$ lower than $1000 \mathrm{ml}$ were successfully weaned when in a stable clinical state and more easily included with a VC higher than $1000 \mathrm{ml}$. We believe this might explain the decreasing success percentages below the level of $1500 \mathrm{ml}$ (selection bias). Chiodo et al. found that $83 \%$ of the patients with FVC $>800 \mathrm{ml}$ were successfully weaned but only $12 \%$ with a FVC $<800 \mathrm{ml}$ [21]. With this and the wide range of patient individual conditions in mind, we emphasise the German guideline for safety reasons. This is confirmed by the fact that lower $\mathrm{VC}$ was also related to longer duration of the weaning (Fig. 3, $p<0.01$ ), more weaning attempts (Table 2, $>2$ attempts mean $850 \mathrm{ml}, p=0.02$ ) and a higher rate of pneumonia at mean $974 \mathrm{ml}(p=0.04)$.

Obese people with a BMI $>25 \mathrm{~kg} / \mathrm{m}^{2}$ often have to deal with a decreased compliance of the respiratory system, reduced lung volumes, higher oxygen consumption, impaired gas exchange, obstructive sleep apnoea and hypopnea [32]. Therefore, this group showed significantly lower success rates. Interestingly, this had no statistical influence on the weaning duration. Regarding the successfully weaned patients, perhaps presence of the tracheostomy and therefore the lack of possible influence of laryngeal and pharyngeal obstruction in addition to sufficient airway management may explain the outcome.

Little is known about the outcome of individuals with SCI and combined COPD specifically, but in general outcomes for COPD patients are worse. Mortality rates are high and time of treatment in ICU or IMCU is prolonged [23]. Severe COPD is also known to be an independent risk factor for an increased duration of weaning and weaning failure [8]. In a cohort of 153 patients admitted to a regional weaning centre, $56 \%$ of the patients with COPD were successfully weaned from the ventilator, $20 \%$ stayed ventilator dependent, and 24\% died in the hospital [11]. In our study, we found that COPD GOLD 3 patients needed significantly more weaning attempts $(p<0.01)$ at comparable results to non-COPD group regarding weaning success (Table 1).

Interestingly, this study did not find significant differences in weaning between those with full and hemi diaphragm function. Fifteen out of $21(71 \%)$ patients with hemiplegia of the diaphragm were successfully weaned compared to 110 out of 135 (81\%) in patients with normal diaphragm function. Patients with hemiplegic diaphragm were on average weaned in 51.2 (41.0) days, 67\% after first weaning attempt, $29 \%$ after the second attempt and $5 \%$ took more than two attempts. Therefore, we assert that patients with diaphragm hemiplegia deserve the same therapy and effort as patients with normal diaphragm function.

\section{Pneumonia}

In our study, pneumonia was not associated with weaning failure, but with a longer duration of the weaning process ( $p$ $<0.001)$ and more weaning attempts $(p<0.001)$. In the literature, respiratory complications are common in people with SCI. Jackson and Groomes reported a $67 \%$ incidence of respiratory complications, particularly pneumonia [9]. In a systematic review written by Berney et al. high respiratory complication rates in those with SCI above C5 and AIS score A were reported [4]. We suggest that the combination of (1) early tracheostomy; (2) early pressure controlled ventilation; and (3) intensive airway management (mucoand secretion clearance therapy with cough assistance) reduces the incidence of pneumonia in individuals with SCI [22].

Surprisingly, in our study, patients using Baclofen and/or Dantrolene developed significantly more pneumonia $(p<0.001)$. Twenty-one percent of those using these medications for spasticity were diagnosed with pneumonia compared to $4 \%$ in patients without such medication. We can assume this is caused by reasons the medication is primarily given, namely, spasticity. In a case report, Britton et al. described that spasticity of trunk muscles appeared to 
have a negative effect on pulmonary function by decreasing chest wall compliance and increasing intra-abdominal pressure with lower VC (reduced diaphragmatic excursion). Furthermore, they state, "oral spasmolytic medications like Baclofen could affect the respiratory centre in the medulla oblongata, which further exacerbate the patient's respiratory compromise. Additionally, insomnia and pain due to severe spasticity reduces overall tolerance or endurance for weaning from the ventilator" [33]. Therefore, this patient group is severely affected with an increased risk for pneumonia before initiating the medication. A further study with more focus on the effect of Baclofen and/or Dantrolene on pneumonia is suggested.

\section{Limitations}

The main limitation of the study is the retrospective monocentric non-controlled design. A multi SCI centre study with even more participants might show more variable results. This study is also limited by some missing measurements regarding BMI (23\%) and VC (15\%). Furthermore, we were not able to differentiate for gender due to statistical reasons (low number of female patients) which is typical of this clientele.

However, other studies are mostly smaller and sometimes of poor quality. Therefore, even given the limitations, we have presented significant results that have implications on patient management and counselling.

\section{Conclusion}

Prolonged weaning outcome of invasively ventilated patients with SCI is not only worsened significantly by level of lesion above $\mathrm{C} 4$, age above 56 years and initial $\mathrm{VC}$ below $1500 \mathrm{ml}$, but also influenced by co-morbidities like obesity and COPD, although these factors do not presuppose failure to wean from a ventilator. Therefore, the discontinuous weaning procedure seems to be a sensible method to wean patients with SCI. On average patients were successfully weaned in 37 days, with pneumonia the most frequent complication, possibly enhanced by simultaneous therapy with Baclofen or Dantrolene. A further study investigating the effect of Baclofen and/or Dantrolene on pneumonia is worthy of further consideration.

The weaning process in people with SCI is influenced by multiple factors. Higher risk of SCI-associated complications such as dysreflexia, septicaemia (e.g., due to spondylodiscitis or pressure sores), and spasticity could prolong or even prevent a successful weaning process. Additionally, regular transfer of a person with SCI in a wheelchair despite invasive ventilation is also a challenge for all disciplines. Therefore, provision of SCI-specific medical and nursing skills are prerequisites to accompanying the weaning in patients with SCI.

Acknowledgements We thank Mrs. Caren Christoffers and Mr. Sören Tiedemann for their assistance in data entry and processing.

\section{Compliance with ethical standards}

Conflict of interest The authors declare that they have no conflict of interest.

\section{References}

1. McMichan JC, Michel L, Westbrook PR. Pulmonary dysfunction following traumatic quadriplegia. J Am Med Assoc. 1980; 243:528-31.

2. Mueller G, de Groot S, van der Woude LH, Perret C, Michel F, Hopman MT. Prediction models and development of an easy to use open-access tool for measuring lung function of individuals with motor complete spinal cord injury. J Rehabil Med. 2012;44:642-6.

3. Hirschfeld S, Tiedemann S, Jürgens N, Thietje, High R. Cervical SCI with invasive ventilation-characteristics within the weaning process. Med Rev. 2012;8:24-2.

4. Berney S, Bragge P, Granger C, Opdam H, Denehy L. The acute respiratory management of cervical spinal cord injury in the first 6 weeks after injury: a systematic review. Spinal Cord. 2011;49:17-29.

5. Schönhofer B, Geiseler J, Dellweg D, Moerer O, Barchfeld T, Fuchs $\mathrm{H}$, et al. Prolongiertes Weaning, S2k-Leitlinie herausgegeben von der Deutschen Gesellschaft für Pneumologie und Beatmungsmedizin e.V. Pneumologie. 2014;68:19-75.

6. Harrop JS, Sharan AD, Scheid EH Jr, Vaccaro AR, Przybylski GJ. Tracheostomy placement in patients with complete cervical spinal cord injuries: American Spinal Injury Association Grade A. J Neurosurg. 2004;100:20-3.

7. Choi HJ, Paeng SH, Kim ST, Lee KS, Kim MS, Jung YT. The effectiveness of early tracheostomy (within at least 10 days) in cervical spinal cord injury patients. J Korean Neurosurg Soc. 2013;54:220-4.

8. Boles JM, Bion J, Connors A, Herridge M, Marsh B, Melot C, et al. Weaning from mechanical ventilation. Eur Respir J. 2007;29:1033-56.

9. Jackson $\mathrm{AB}$, Groomes TE. Incidence of respiratory complications following spinal cord injury. Arch Phys Med Rehabil. 1994;75:270-5.

10. Cotton BA, Pryor JP, Chinwalla I, Wiebe DJ, Reilly PM, Schwab $\mathrm{CW}$. Respiratory complications and mortality risk associated with thoracic spine injury. J Trauma. 2005;59:1400-9.

11. Pilcher DV, Bailey MJ, Treacher DF, Hamid S, Williams AJ, Davidson AC. Outcomes, costs and long-term survival of patients referred to a regional weaning centre. Thorax. 2005;60:187-92.

12. Cooper LM, Linde-Zwirble WT. Medicare intensive care unit use: analysis of incidence, costs and payment. Crit Care Med. 2004;32:2247-53.

13. Wagner DP. Economics of prolonged mechanical ventilation. Am Rev Respir Dis. 1989;140:S14-8.

14. Cohen IL, Booth FV. Cost containment and mechanical ventilation in the United States. New Horiz. 1994;2:283-90.

15. McCaughey EJ, Purcell M, McLean AN, Fraser MH, Bewick A, Borotkanics RJ, et al. Changing demographics of spinal cord injury over a 20-year period: a longitudinal population-based study in Scotland. Spinal Cord. 2016;54:270-6. 
16. Montoto-Marqués A, Ferreiro-Velasco ME, Salvador-de la Barrera S, Balboa-Barreiro V, Rodriguez-Sotillo A, Meijide-Failde R. Epidemiology of traumatic spinal cord injury in Galicia, Spain: trends over a 20-year period. Spinal Cord. 2017;55:588-94.

17. Jackson B, Dijkers M, Devivo MJ, Poczatek RB. A demographic profile of new traumatic spinal cord injuries: change and stability over 30 years. Arch Phys Med Rehabil. 2004;85:1740-8.

18. DeVivo MJ. Epidemiology of traumatic spinal cord injury: trends and future implications. Spinal Cord. 2012;50:365-72.

19. Hirschfeld S, Exner G, Tiedemann S, Thietje R. Langzeitbeatmung querschnittgelähmter Patienten-Ergebnisse und Ausblicke aus 25 Jahren Erfahrung mit klinische rund außerklinischer Beatmung. Trauma Berufskrankh. 2010;12:177-81.

20. Como JJ, Sutton ERH, McCunn M, Dutton RP, Johnson SB, Aarabi B, et al. Characterizing the need for mechanical ventilation following cervical spinal cord injury with neurologic deficit. J Trauma. 2008;59:912-6.

21. Chiodo E, Scelza W, Forchheimer M. Predictors of ventilator weaning in individuals with high cervical spinal cord injury. J Spinal Cord Med. 2008;31:72-7.

22. Fromm B, Hundt G, Gerner HJ, Baer GA, Exner G, Bötel U, et al. Management of respiratory problems unique to high tetraplegia. Spinal Cord. 1999;37:239-44.

23. Schönhofer B, Euteneuer S, Nava S, Suchi S, Köhler D. Survival of mechanically ventilated patients admitted to a specialised weaning centre. Intensive Care Med. 2002;28:908-16.

24. Rowland JW, Hawryluk GWJ, Kwon B, Fehlings MG. Current status of acute spinal cord injury pathophysiologie and emerging therapies: promise on the horizon. Neurosurg Focus. 2008;25:E2.

25. Kirshblum S, Burns SP, Biering-Sorensen F, Donovan W, Graves $\mathrm{DE}$, Jha $\mathrm{A}$, et al. International standards for neurological classification of spinal cord injury, revised 2011. J Spinal Cord Med. 2011;34:535-46.

26. Miller MR, Hankinson J, Brusasco F, Burgos F, Casaburi R, Coates A, et al. Standardisation of spirometry. Eur Respir J. 2005;26:319-38.

27. Vivier E, Mekontso Dessap A, Dimassi S, Argas F, Lyazidi A, Thille AW, et al. Diaphragm ultrasonography to estimate the work of breathing during non-invasive ventilation. Intensive Care Med. 2012;38:796-803.

28. Kim WY, Suh HJ, Hong SB, Koh Y, Lim CM. Diaphragm dysfunction assessed by ultrasonography: influence on weaning from mechanical ventilation. Crit Care Med. 2011;39:2627-30.

29. Gutierrez CJ, Harrow J, Haines F. Using an evidence-based protocol to guide rehabilitation and weaning of ventilator-dependent cervical spinal cord injury patients. J Rehabil Res Dev. 2003;40:99-110.

30. Dalhoff K, Ewig S. Epidemiology, diagnosis and treatment of adult patients with nosocomial pneumonia S3 Guideline of the German Society for Anaesthesiology and Intensive Care Medicine, the German Society for Infectious Diseases, the German Society for Hygiene and Microbiology, the German Respiratory Society and the Paul-Ehrlich-Society for Chemotherapy. Pneumologie. 2009;66:707-65.

31. Wicks AB, Menter RR. Long-term outlook in quadriplegic patients with initial ventilator dependency. Chest. 1986; 90:406-10.

32. Lewandowski $\mathrm{K}$, Lewandowski $\mathrm{M}$. Intensive care in the obese. Best Pract Res Clin Anaesthesiol. 2011;25:95-108.

33. Britton D, Goldstein B, Jones-Redmond J, Esselman P. Baclofen pump intervention for spasticity affecting pulmonary function. $\mathrm{J}$ Spinal Cord Med. 2005;28:343-7. 